Violence

\section{Injury research explains conflicting violence trends}

\section{J Shepherd, V Sivarajasingam}

\section{Police records should not be used to measure violence}

7 his commentary explains conflicting trends in violence over the past decade as derived from the two official sources of information: household crime surveys designed to identify citizens' experience of crime and police data. Police records, rather than representing a reliable measure of trends in violence, are a product of police activity-increasingly prompted by better surveillance and targeting, increased numbers of police, and changes in recording practices. Injury data from emergency departments are an objective measure of harm and should be used to target local violence prevention resources.

\section{TRENDS IN VIOLENCE}

Measuring interpersonal violence is an important objective: there is keen interest in trends among policy makers; a broad range of criminal justice, community safety, and victim organizations; the media; and among the public. However, the two traditional and high profile violent crime measures-annual crime surveys and police data-have shown conflicting trends. ${ }^{12}$ According to the British Crime Survey (BCS), for example, violence in England and Wales fell by $36 \%$ from a peak in 1995 to 2004. ${ }^{1}$ In contrast, violent offences recorded by the police in England and Wales almost doubled from 1996 to $2004 .^{2}$ Similarly in the US, as convictions for violent offences have increased, reflecting greater police activity, so violence rates have fallen. ${ }^{3}$ Public health interest in violence is reflected in national electronic injury surveillance systems which have been developed, for example in Australia (Basic Routine Injury Surveillance System), Canada (Canadian Hospitals Injury Reporting and Prevention Programme (CHIRPP)), and the US, but these systems are not designed to complement police and national crime survey violent crime statistics or to contribute to prevention. ${ }^{4-7}$ This is because it has not been recognized until recently that a principal contribution of health services to violence prevention is information about those many - even a majority of some offences-which result in emergency department treatment but which are not reported to and therefore not recorded by the police. Research published in Injury Prevention and elsewhere shows that police recording depends on the circumstances of violence-where and why it happened, and on the age and sex of the injured. ${ }^{89}$ It is not even safe to assume that the most serious violence will be reported: a data matching study in Atlanta, USA showed that $13 \%$ of shootings which led to emergency department treatment, did not appear in citywide police records and a study of violence in Bristol, UK found no significant correlation between injury severity and outcome in the criminal justice system: even the most severe offences may not be detected by the police. ${ }^{10}{ }^{11}$ This mismatch between the only local criminal justice source of data (police statistics) and injury data has major implications for policy and practice: that emergency department data can provide unique insights of community violence, ${ }^{12}$ and that in aggregate form they can provide new measures of regional, national, and international violence. ${ }^{13}$ They can contribute substantially to local prevention. $^{14}$

Importantly, implementation of these measures is shedding light on confusing messages about trends in violence from official sources. National assault injury surveillance however, a relatively new source of data on violence in England and Wales which is based on a representative sample of major emergency departments, has shown a $12 \%$ decrease, from an estimated 351000 assault related attendances in 2000 to 309000 in $2004,{ }^{15}$ after a five year period when no significant trends were identified..$^{13}$ There were significant decreases in violence from 2000-04 affecting males, females, males and females aged 0-17 years, females aged 1830 years, and females aged 51 years and over from this perspective. ${ }^{15}$ Increases in violence related harm were not detected in any age group, apart from females aged $11-17$ between 1995 and 2000. ${ }^{13}$

\section{DIFFERENCES IN RECORDING VIOLENCE}

The BCS, like most victimization surveys including the National Crime Victimization Survey (NCVS) in the US, is based on visits to representative households by interviewers who ask residents about their experiences of crime-regardless of whether offences have been reported to or recorded by the police-in the previous 12 months. ${ }^{16}$ Crime surveys are a principal source of data on violence, entirely separate from police data (the other traditional source). Violence categories in the BCS include Acquaintance, Domestic and Stranger violence, and Mugging. As in most victimization surveys, it is difficult to represent the population adequately: some responders cannot be located at home and others refuse to be interviewed. Victimization rates for non-responders may differ. The BCS is large by the standards of most surveys, but its estimates are imprecise, in particular for rarer offences such as serious violence. In general crime surveys undercount crime where victim and offender know each other. Responders may not think of these offences as real crimes and can be reticent with interviewers. ${ }^{17}$ Various factors stand in the way of accurate answers: a respondent may fabricate an offence, fail to realise that an incident meets the terms of the questions, remember the incident but think it happened before the reference period, remember an earlier incident as being within the reference period, or simply forget a relevant incident. ${ }^{17}$ However, the BCS has been consistent in the way violence is recorded since its first sweep in 1982 and decreases in violence since 2000 identified from the BCS and emergency department data are similar.

Decisions to report violence to the police depend on location of incident, being able to identify an offender, whether it is thought of as a crime, willingness to have own conduct investigated, and fear of reprisals. ${ }^{18}$ Once a violent crime is reported, what a police officer decides to do will depend not only on the circumstances of the incident but also on local and national police policies. Hence, there is no guarantee that the offence, once reported, will necessarily find its way into the official statistics.

Importantly, both sets of official statistics depend to varying degrees on subjective factors. Neither is an objective measure of harm. Data from emergency departments provide this perspective and do not depend on perception or recall that an offence has been committed but on the presence of injury deemed to require emergency department treatment, providing reliable objective criteria. Information about community violence is recorded in emergency departments shortly after injury when the event is fresh in the minds of the injured and those who accompany them. In the UK all current emergency department software packages categorize cause of injury as accident or assault permitting reliable electronic data entry, facilitating this new approach. ${ }^{13}$ Evidence 
of objectivity has come from investigations of sensitivity and specificity of assault data recording, and from correlations with panel data relating to known risk factors for injury from violence, such as unemployment. ${ }^{19}$ Also, other emergency department based injury surveillance-for example, the CHIRPP-has shown that as of 1996, at the 14 hospitals for which estimates were available, the median injury capture was $88 \%$ (range $24 \%$ 100\%). ${ }^{6}$ Limitations of emergency department violence surveillance include absence of data on incidents in which no injury or minor injury not deemed to require emergency department treatment is sustained, and the influence of emergency department accessibility for the injured. ${ }^{20}$ Also, emergency department violence data generally lack completeness: location of incident, details of the perpetrator, or the relationship between the injured and the perpetrator are usually not recorded. There are also problems with ascertainment of some types of violencefor example, violence directed towards children and sexual violence may not be disclosed.

\section{FACTORS AFFECTING POLICE RECORDING OF VIOLENCE}

Since 1990, public space CCTV surveillance has been installed in almost all UK towns and city centres where most violence occurs, providing the public and local government with evidence of offending. CCTV evaluation and knowledge of the sequence of events leading to assault injury suggests an explanation for the conflict with trends derived from police violence data. Opposite trends in violence have been identified from emergency department and police data from English cities with public space CCTV surveillance: CCTV installation was associated with increased police detection of violence ( $11 \%$, ratio 1.16 ; $95 \%$ CI 1.08 to 1.24 ) but decreased emergency department treatment for injuries $(-3 \%$, ratio 0.96 ; $95 \% \mathrm{CI}$ 0.93 to 0.99$).{ }^{21}$ In contrast, in cities without CCTV overall, there was a significant increase in assault related emergency department attendance ( $11 \%$, ratio 1.11; $95 \%$ CI 1.08 to 1.14 ) but no significant change in violence recorded by the police (5\%, ratio 1.06 ; $95 \%$ CI 0.99 to 1.13 ). ${ }^{21}$ Increased surveillance and prompt police intervention explain the apparent conflicting trends in the study: the benefit of CCTV lies less in preventing such offences (which it is argued will occur anyway because of their impulsive nature and the role of alcohol) and more in facilitating more frequent and faster police responses to assaults in public places and their precursors-for example, arguments. Since severity of injury increases as numbers of blows increase, ${ }^{22}$ limiting incident duration reduces the incidence and seriousness of injury. These findings also show the importance of reducing firearm, knife, and other weapon carrying to a minimum, not only to prevent the serious injuries which result but also because their use shortens violence duration and the opportunity for pre-emptive police intervention. The fact that violence, almost uniquely, generates injuries over a period of time is an opportunity for intervention.

Other factors, in addition to improved surveillance, also explain increases in violence recorded by the police, including increased police activity stemming from substantial increases in police numbers, for example in England and Wales to 138000 in 2004, from 127000 in 1997 and an increase in the proportion of violent crimes reported, from 35\% in 1999 to $41 \%$ in $2002 / 03$. Police targetting of alcohol related violence increased after 2000. Furthermore, between 1999 and 2002/03, also in England and Wales, recording of reported violent crime increased from $36 \%$ to $53 \%$ reflecting a requirement for the police to record as violence crimes of common assault and harassment. $^{23}$ Additionally, in 2002, National Crime Recording Standards (NCRS) were introduced to promote recording consistency and to allow a more victim led approach—by recording alleged as well as proven offences; this led to an estimated inflation of $23 \%$ in recorded violent crime in 2002/03 alone. ${ }^{23}$

\section{CONCLUSIONS}

Police records of violence are a product of police surveillance, targetted activity, and recording practices. They should not be used as a measure of underlying trends in violence. Far from representing a cause of concern, increases in violence recorded by the police are often associated with less harm. We now know that the media, which tend to report the most controversial findings — often increasing fear of crime $^{24}$-act irresponsibly if increases according to police data are interpreted as real increases. Governments should use emergency department data as an objective indicator of violence related harm and to inform local violence prevention.

\section{ACKNOWLEDGEMENT}

The authors thank Mr Jon Simmons, Home Office, London for comments on this manuscript.

Injury Prevention 2005;11:324-325.

doi: 10.1136/ip.2005.009761

\section{Authors' affiliations}

J Shepherd, V Sivarajasingam, Violence

Research Group, Department of Oral Surgery, Medicine and Pathology, Cardiff University, Cardiff, UK

Correspondence to: Professor J P Shepherd, Violence Research Group, Department of Oral
Surgery, Medicine and Pathology, Cardiff University, Hearth Park, Cardiff CF14 4XY, UK; shepherdjp@cardiff.ac.uk

Accepted 14 September 2005

Conflicting interests: none.

\section{REFERENCES}

1 Dodd T, Nicholas S, Povey D, et al. Crime in England and Wales 2003/2004. Home Office Statistical Bulletin. London: HMSO, 2004.

2 Clegg M, Finney A, Thorpe K. Crime in England and Wales: quarterly update to December 2004. London: HMSO, 2005

3 Farrington DP, Langan PA, Wikstrom PO. Changes in crime and punishment in America, England and Sweden between the 1980s and the 1990s. Studies on Crime and Crime Prevention 1994.

4 Lloyd LE, Graitcer PL. The potential for using a trauma registry for injury surveillance and prevention. Am J Prev Med 1989;5:34-7.

5 Harrison J, Tyson D. Injury surveillance in Australia. Acta Pediatr Jpn 1993:35:171-8.

6 Mackenzie SG, Pless IB. CHIRPP: Canada's principal injury surveillance program. Inj Prev 1999;5:208-13.

7 World Health Organization. Preventing violence: a guide to implementing the recommendations of the World Report on Violence and Health. Geneva: WHO, 2004:12

8 Sutherland I, Sivarajasingam V, Shepherd JP. Recording of community violence by medical and police services. Inj Prev 2002;8:246-7.

9 Shepherd JP, Scully C, Shapland M. Recording of violent offences by the police: an accident and emergency department perspective. Med Sci Law 1989:29:251-7.

10 Kellerman AL, Bartolomeos K, Fuqua-Whitley D, et al. Community-level firearm injury surveillance: local data for local action. Ann Emerg Med 2001;38:423-9.

11 Shepherd JP. Violence: the relation between seriousness of injury and outcome in the criminal justice system. J Accid Emerg Med 1997; 14:204-8.

12 Shepherd JP. Emergency medicine and police collaboration to prevent community violence. Ann Emerg Med 2001;38:430-7.

13 Sivarajasingam V, Shepherd JP, Matthews K, et al. Trends in violence in England and Wales 1995-2000: an accident and emergency perspective. J Pub Health Med 2002;24:219-26.

14 Warburton AL, Shepherd JP. Development, utilisation and importance of accident and emergency derived assault data in violence management. Emerg Med J 2004;21:473-7.

15 Sivarajasingam V, Shepherd JP, Walker R, et al. Trends in violence in England and Wales 20002004. An accident and emergency perspective. Cardiff: University of Cardiff, 2005.

16 Mirrlees-Black C, Budd T, Partridge S. The 2000 British Crime Survey. London: HMSO, 2001

17 Sparks R, Genn H, Dodd D. Surveying victims. London: Wiley, 1977.

18 Mayhew P, Elliot D, Dowds L. The 1988 British Crime Survey. Home Office Research Study No 111. London: HMSO).

19 Sivarajasingam V. Trends in assault injury and the effects of urban CCTV, PhD thesis. Cardiff: University of Wales College of Medicine, 2001

20 Lyons RA, Lo SV, Heaven M. Injury surveillance in children-usefulness of a centralised database of accident and emergency attendances. Inj Prev 1995; 1:173-6.

21 Sivarajasingam V, Shepherd JP, Matthews K. Effect of urban closed circuit television on assault injury and violence detection. Inj Prev 2003;9:312-16.

22 Shepherd JP, Shapland M, Pearce NX, et al. Pattern, severity and aetiology of iniuries in victims of assault. J R Soc Med 1990:83:75-9.

23 Home Office. Violence against the person-long term national recorded crime trends, London. Research Development and Statistics Directorate 2005. Available at http://www.crimestatistics.org. uk/output/Page38.asp (accessed October 2005).

24 Heath L. Impact of newspaper crime reports on fear of crime: a multimethodological investigation. J Personal Soc Psychol 1984:47:263-6. 